\title{
HÁBITOS ALIMENTARES E DE HIGIENE ORAL INFLUENCIANDO A SAÚDE BUCAL DA GESTANTE
}

\author{
Norma Suely Falcão O Meloํ, Rafaella Ronchi², Carolina de Souza Mendes ${ }^{3}$, Verônica de Azevedo Mazza ${ }^{4}$
}

RESUMO: Este trabalho foi desenvolvido em 2003 e teve como objetivo a investigação dos hábitos alimentares e da negligência da higiene oral como fatores de risco para o desenvolvimento de cárie e doença periodontal em pacientes grávidas. Foram avaliadas 34 mulheres em período de gestação, entre 2 e 9 meses, usuárias de uma Unidade de Saúde Pública da região metropolitana de Curitiba. Foi elaborado e aplicado para a amostra, um instrumento de avaliação com um odontograma para realização de exame simplificado, e que apresentava perguntas sobre hábitos alimentares e de higiene bucal. Os resultados mostraram que 56\% das gestantes tinham cárie, 44\% possuíam uma higiene deficiente e $56 \%$ não utilizavam fio dental. A baixa freqüência de consulta ao dentista foi de $77 \%$, e é demonstrada pelo índice de cálculo de 56\%. Das mulheres analisadas, 100\% utilizavam o açúcar para adoçar os alimentos e 53\% apresentavam uma alta freqüência diária de ingestão de açúcar.

PALAVRAS-CHAVE: Gestante; Promoção da saúde; Higiene bucal

\section{FOOD HABITS AND ORAL HYGIENE INFLUENCING PREGNANT WOMEN'S ORAL HEALTH}

\begin{abstract}
This work was carried out in 2003 and objectified to investigate food habits and the disregard of the oral hygiene as risk factors for caries development and periodontal illness in pregnant patients. 34 women were assessed, between 2 and 9 months of gestation, users of a Public Health Unit in Curitiba Metropolitan Area. The authors elaborated and applied, in all the sample, a protocol with odontogram for accomplishment of simplified examination, and presented questions on food habits and oral hygiene. The results shoed that $56 \%$ of the pregnant had caries, $44 \%$ had poor hygiene and $56 \%$ did not use dental floss. Low frequency to the dentist's was $77 \%$, and is demonstrated by the index of calculation of 56\%. From the analyzed women, $100 \%$ used sugar to sweeten food and $53 \%$ presented high daily frequency of sugar intake.
\end{abstract}

KEYWORDS: Pregnant women; Health promotion; Oral hygiene.

\section{HÁBITOS ALIMENTARES Y DE HIGIENE ORAL INFLUYENDO EN LA SALUD BUCAL DE LA GESTANTE}

RESUMEN: Este trabajo tuvo como objetivo la investigación de los hábitos alimenticios y de la negligencia de la higiene bucal como factores de riesgo para el desarrollo de caries y de enfermedades periodontales en pacientes gestantes. Fueron evaluadas 34 mujeres en el periodo de gestación, entre segundo y noveno mes, pacientes de la Unidad de Salud Pública. Fue elaborado y aplicado un protocolo con odontograma para la realización de un examen simplificado, que presentava preguntas sobre hábitos alimenticios y de salud bucal. Los resultados mostraron que $56 \%$ de las gestantes tenían caries, $44 \%$ tenían una higiene deficiente y $56 \%$ no utilizaban hilo dental. Una baja frecuencia de consulta al dentista (77\%) fue demostrada por el índice del cálculo de 56\%. Todas las mujeres analizadas utilizaban azúcar para endulzar los alimentos y 53\% presentaban una elevada frecuencia diaria de ingestión de este.

PALABRAS CLAVE: Mujeres embarazadas; Promoción de la salud; Higiene bucal.

\footnotetext{
${ }^{1}$ Cirurgiã-dentista. Prof ${ }^{a}$ Adjunta do Departamento de Estomatologia da Universidade Federal do Paraná - UFPR.

${ }^{2}$ Cirurgiã-dentista pela UFPR.

${ }^{3}$ Cirurgiã-dentista pela UFPR.

${ }^{4}$ Enfermeira. Mestre em Enfermagem. Professora do Departamento de Enfermagem da UFPR. Membro do Grupo de Estudos, Família, Saúde, Desenvolvimento - GEFASED.
}

Autor correspondente:

Norma Suely Falcão O Melo

Rua Lothário Meisner 3400 - CEP 80210-170 - Curitiba - PR

Email: normamel@terra.com.br 


\section{INTRODUÇÃO}

A gestação é um período em que ocorrem intensas transformações no corpo e na mente da mulher. As alterações fisiológicas favorecem o aparecimento de doenças bucais como a cárie e doença periodontal. Devido à elevação das taxas de progesterona ocorrem alterações na micro vascularização que se mostram na gengiva, por intermédio de um processo inflamatório em presença da placa bacteriana. Este processo promove um potencial de agressão ao tecido gengival, que se encontra alterado, favorecendo o aparecimento de doença gengival, principalmente a gengivite gravídica. Mudanças teciduais da mãe, o desenvolvimento do feto e da placenta e o aumento da atividade metabólica levam a um consumo de nutrientes adicionais de $15 \%$ em relação ao estado não gestacional. Ainda, a ingestão de alimentos aumenta em quantidade e freqüência diária, principalmente aqueles do grupo dos carboidratos. Deste modo, pode-se relacionar o período da gravidez com uma maior incidência de lesões cariosas ${ }^{(1,2)}$.

Condições predisponentes à cárie dentária e às doenças periodontais têm sido observadas na gestação sendo que algumas delas a negligência na higienização bucal, alterações na dieta, hiperacidez do meio bucal e alterações hormonais que favorecem a ocorrência de náuseas e vômitos. Esses fatores, unidos, demonstram que a paciente grávida encontra-se em uma situação especial e requer cuidados redobrados dos profissionais de saúde em relação à higiene e às doenças bucais, principalmente pelo cirurgião-dentista. Verificou-se que as gestantes na faixa etária de 20 a 25 anos de idade alcançam um índice de cárie, ou seja, o CPO, de $25,88 \%$, também, determinou-se um índice de 18,2\% para a mesma faixa etária e de $48,78 \%$ de prevalência de doença periodontal ${ }^{(3-5)}$.

$\mathrm{Na}$ fase gestacional ocorrem alterações hormonais que irão alterar a resposta do periodonto aos agentes irritantes. Diferentemente da flora que desencadeia lesões cariosas, a flora associada à doença periodontal tem seu aumento favorecido pelo aumento de estrogênio e progesterona. Estudos in vitro demonstraram que esses hormônios servem de nutrientes particularmente, para essas bactérias. $\mathrm{O}$ tumor gravídico, massa tumoral que se assemelha ao granuloma piogênico, está relacionado a um trauma ou irritação por placa bacteriana ou cálculo, juntamente com as alterações hormonais responsáveis pela resposta tecidual exagerada ${ }^{(2)}$.

Com base nas reflexões anteriores, este trabalho tem como objetivo a investigação de hábitos alimentares e a negligência na higiene oral como fatores de risco para desenvolvimento de cárie e doença periodontal em pacientes grávidas.

\section{REVISÃO DA LITERATURA}

Durante a gestação ocorrem intensas mudanças físicas, psicológicas e sociais para os pais do futuro bebê, que vão desde a aceitação da gravidez até a adaptação à nova situação de ser pai e mãe. Este evento gera na mãe, entre outros sentimentos, a ansiedade, a qual também está associada ao processo fisiológico da gravidez e faz com que a mulher aumente a ingestão de alimentos, principalmente os que favorecem o desenvolvimento de doenças bucais ${ }^{(6-8)}$.

Uma Unidade Básica de Saúde tem como função desenvolver um programa sistematizado de atenção à saúde, abordando o processo normal de saúde como também as principais causas de danos à saúde, uma vez que se constitui como a porta de entrada da clientela para o Sistema Único de Saúde (SUS). Na metade dos anos 70 do século passado, a abordagem do sistema de saúde começou a ser questionada, tendo por base as novas concepções do processo saúde-enfermidade-cuidado, que são baseadas na biologia humana, estilo de vida, ambiente e serviços de saúde. Um ponto crítico deste modelo leva à reflexão sobre promoção da saúde e prevenção de doenças. A promoção da saúde possui um enfoque mais amplo e abrangente, pois deve identificar e considerar os macro-determinantes do processo de saúde-doença, buscando transformá-los favoravelmente na direção da saúde. A prevenção tem por finalidade a isenção de doenças pelo indivíduo. Portanto, a saúde deve ser considerada para além da ausência de enfermidades e, antes de tudo, como um recurso para a vida. A essência da promoção da saúde é levar a um estado maior do fortalecimento estrutural, de ampliar a capacidade funcional, de estimular sensações subjetivas de bemestar e desenvolvimento individual e coletivo. A promoção da saúde bucal tem seguido ao modelo químioparasitário da cárie e as medidas preventivas são abordadas dentro deste modelo e do conceito prevenção de doenças ${ }^{(9-11)}$.

Há que se ressaltar que, se a gestante não possui uma saúde bucal adequada e não compreende o conceito de saúde, ela provavelmente terá dificuldades para realizar e praticar medidas de prevenção de doenças e promoção da sua saúde bucal, ao mesmo tempo esta mulher terá dificuldades em fazer com que seu filho 
cresça com essa mesma preocupação ${ }^{(12)}$. Um das doenças bucais do bebê mais prevalentes é a cárie de peito ou da mamadeira e que têm como causa principal a infecção da cavidade bucal das crianças por seus pais ou cuidadores, com bactérias que colonizam a boca. Esta contaminação se dá no ato da limpeza de chupeta ou durante a prova dos alimentos. A mãe exerce um papel importante no núcleo familiar e é uma formadora de opiniões, determinando muitos dos comportamentos que seus filhos terão. Considerando também que uma criança irá adotar a dieta altamente cariogênica da família e que seus hábitos serão copiados por seus filhos, então, uma gestante bem informada sobre a sua saúde geral e bucal é o primeiro passo para uma população livre de cárie ${ }^{(13)}$. O período da gravidez favorece $\mathrm{o}$ aumento da incidência de lesões cariosas, não pelo acréscimo da microbiota oral ou de sua patogenicidade, mas pelo aumento da quantidade de placa bacteriana devido aos descuidos da gestante com sua higiene bucal ${ }^{(2)}$.

Através de entrevistas diretas com um grupo de gestantes cadastradas pela Secretaria de Saúde do município de Araçatuba - $\mathrm{SP}^{(14)}$, detectou-se a percepção que as mesmas tinham a respeito da saúde bucal. Das 60 gestantes entrevistadas, 71,66\% diziam conhecer como a cárie é formada, e sobre a ação do flúor, $86 \%$ responderam que sabiam que ele previne a cárie e, destas apenas 3,33\% tinham a informação de que o flúor é encontrado na água de beber, embora a cidade que residem tenha água fluoretada há mais de 25 anos. Foram também pesquisadas, com resultados aquém dos esperados, informações acerca do primeiro molar permanente, da dieta, do principal horário de escovação, da amamentação, entre outros. A mãe tem papel-chave na família, especialmente em relação às questões de saúde. Considera-se que a gestação é um período ímpar na vida da mulher, no qual ela se encontra receptiva à incorporação de novas atitudes e comportamentos. Por isso, torna-se extremamente importante o envolvimento de mulheres grávidas em programas de promoção da saúde. Destacamos a relevância de programas que venham a interferir na quebra da cadeia de transmissibilidade da cárie, a partir de medidas preventivo-educativas, de maneira que a mãe/gestante possa atuar como agente multiplicador de informações de promoção da sua saúde e de sua família $^{(14)}$.

$\mathrm{O}$ atendimento às necessidades de tratamento na gravidez deve receber especial atenção, com o intuito de promover a saúde bucal e a motivação e, conseqüentemente, contribuir para minimizar a provável transmissibilidade de microrganismos bucais patogênicos para a criança, obtendo assim, prevenção primária das principais doenças bucais ${ }^{(15)}$.

Ao avaliar a saúde bucal em gestantes, um estudo mostrou que o índice tinha uma íntima relação com a saúde geral da mulher e relata que isto pode influenciar diretamente a saúde do bebê, inclusive a bucal. Face à evolução dos materiais odontológicos e restauradores, propõe-se tratamentos preventivos e curativos à gestante, utilizando técnicas alternativas já empregadas de forma eficiente em outros grupos populacionais. Esses métodos, de baixo custo operacional, fácil aplicação e grande abrangência social, podem ser implementados nos serviços de saúde coletiva, vinculados a programas de assistência integral à gestante e ao bebê visando à atenção precoce à saúde do bebê $\hat{e}^{(16)}$.

A correlação entre a experiência de cárie de mães e filhos foi demonstrado ser positiva, em um estudo ${ }^{(17)}$, através de avaliação de 50 pares mãe-filho, quando se observou índices de cárie (CPOS modificado), de placa visível e de sangramento gengival. O resultado encontrado foi de mães apresentando uma higiene bucal deficiente e $50 \%$ dos filhos sem receber nenhum tipo de higienização bucal. A dieta dos pares mãe-filho era extremamente cariogênica e 76\% adicionavam açúcar nos alimentos de seus filhos. $\mathrm{O}$ desconhecimento das mães com relação ao conceito de que a cárie é uma doença transmissível, e que elas próprias são os vetores principais de transmissão, reforça a idéia de que a Odontologia deva voltar-se para a educação e cuidados preventivos a partir da gestante.

\section{METODOLOGIA}

Trata-se de uma pesquisa descritiva com análise quantitativa. A pesquisa descritiva pretende aprofundar o conhecimento sobre uma dada realidade, descrever seus fenômenos ${ }^{(18)}$. Esta foi realizada de março a dezembro de 2003, em uma Unidade de Saúde da rede pública de um município da região metropolitana de Curitiba, Paraná. Nesta unidade não havia prestação de serviços odontológicos, apesar de existir espaço físico para a instalação de um consultório da especialidade. O programa de promoção da saúde e prevenção de doenças não contemplava ações para a área da saúde bucal.

O presente estudo teve uma amostragem de 34 mulheres em período gestacional entre 2 a 9 meses e com faixa etária entre 18 a 35 anos. Para o desenvolvimento desta pesquisa, atendemos os 
preceitos da Resolução 196, de 10 de outubro de 1996, sobre as diretrizes e normas reguladoras de pesquisas envolvendo seres humanos do Conselho Nacional de Saúde, que tem mérito de dar ênfase aos compromissos éticos com os sujeitos da pesquisa ${ }^{(19)}$.

Para o levantamento dos dados foi empregado um instrumento (Anexo A) elaborado pelas autoras. A primeira parte do instrumento contém perguntas de identificação, a segunda está relacionada a hábito de higiene oral, dieta e tabagismo e a terceira sobre doença bucal, na qual foram avaliadas as condições de saúde bucal das participantes, através de um exame simplificado por inspeção visual. Este procedimento foi realizado em uma sala com condições adequadas de iluminação. Para o registro do índice de cárie, placa e condições periodontais foi utilizado um odontograma (Anexo B).

Os dados obtidos foram tratados por meio de análise quantitativa, baseada na freqüência e percentagem das respostas dos sujeitos e dos dados obtidos nos exames realizados, apresentados em gráficos e discutidos segundo a literatura.

\section{DISCUSSÃO DOS RESULTADOS}

Identificamos, nos dados apresentados a seguir, a qualidade dos cuidados com higiene bucal,,escovação e uso de fio dental. A Figura 1, mostra que $50 \%$ das gestantes relatavam uma freqüência de escovação dentária boa.

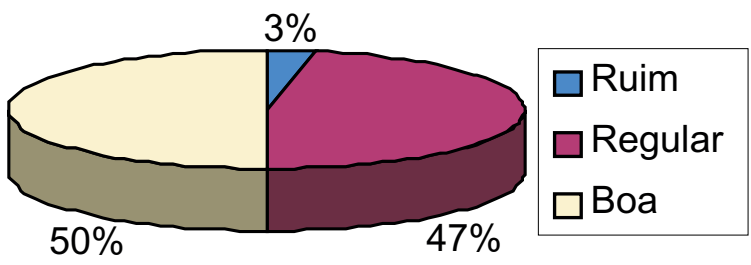

Figura 1 - Freqüência da escovação dentária pelas gestantes. Curitiba, 2003

Apesar das gestantes referirem uma qualidade da escovação, a Figura 2, mostra que apenas $44 \%$ das entrevistadas utilizam o fio dental durante a escovação. A limpeza das faces livres dos dentes tem, na escova dentária, o seu principal agente de limpeza, mas esta por si só não controla a placa bacteriana em todas as superfícies dentárias, até mesmo quando a técnica da escovação é considerada eficiente. Opinando sobre o assunto, alguns autores afirmam que nos dias de hoje a escovação dos dentes com fio e fita dentários são os meios mais eficientes para remover a placa bacteriana da face dos dentes ${ }^{(20)}$.

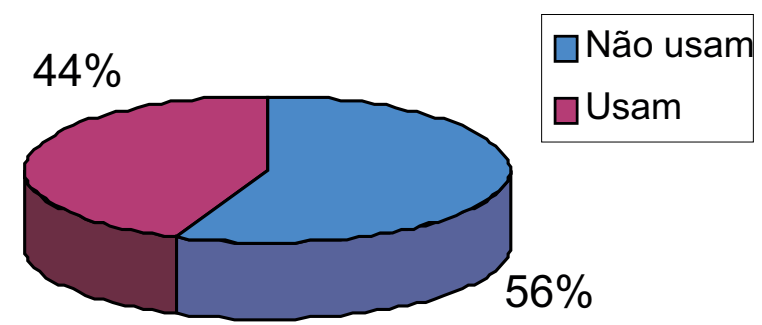

Figura 2 - Freqüência do uso de fio dental pelas gestantes. Curitiba, 2003

Observamos que $50 \%$ das gestantes possuíam uma freqüência ruim de escovação. Apesar de 50\% apresentarem uma higiene bucal boa, 56\% não utilizavam fio dental durante a escovação. Do total das pacientes avaliadas, $70 \%$ possuíam uma higiene bucal entre ruim (deficiente) e regular, Figura 3, apesar do relato da alta freqüência de escovação.
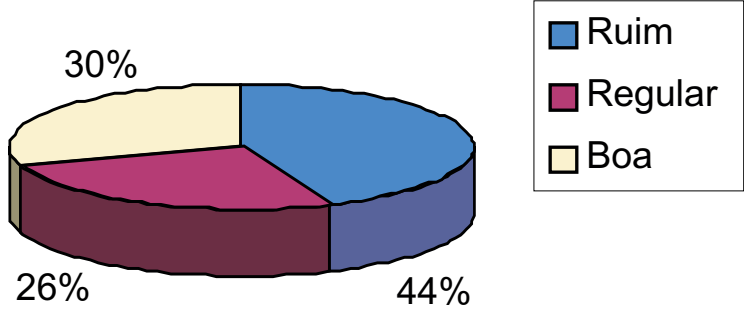

Figura 3 - Freqüência da higiene oral das gestantes. Curitiba, 2003

A última avaliação dentária realizada por dentista foi relatada por $56 \%$ das gestantes como tendo ocorrido entre 1 a 5 anos, e $15 \%$ realizaram sua última consulta há mais de 5 anos, Figura 4. Isto demonstra o risco à doença periodontal avançada demonstrado através do índice de cálculos (tártaro) e sangramento observado em $56 \%$ das gestantes, Figura 5.

Os dados referentes à freqüência das gestantes à consulta ao dentista tornam-se ainda mais relevante, pois existem alterações relacionadas a esta fase da vida da mulher que interferem diretamente na saúde bucal. O período gestacional é considerado de alto risco para a ocorrência da cárie, não pelo aumento da microbiota oral ou mesmo da sua patogenicidade, mas pelo aumento da quantidade de placa bacteriana devido aos descuidos da gestante com sua higiene bucal(2). 


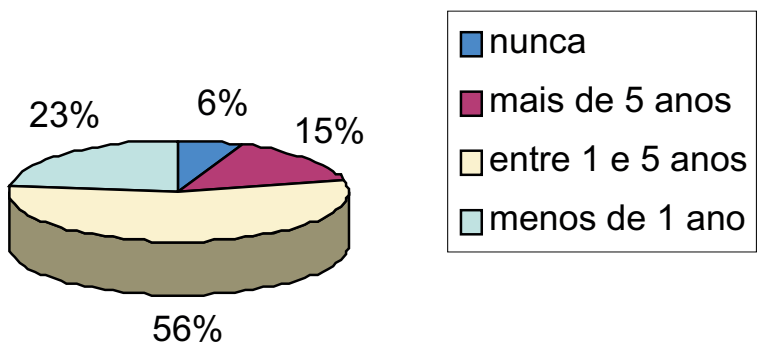

Figura 4 - Freqüência de consultas ao dentista pela gestante. Curitiba, 2003

$\mathrm{O}$ alto índice de cálculos verificado neste estudo, de cerca de $56 \%$, pode ser devido à baixa freqüência de consultas ao dentista, pois $21 \%$ das gestantes ou nunca foram ou estiveram no dentista há mais de 5 anos. As mulheres grávidas que desenvolvem doenças periodontais têm uma grande possibilidade de dar à luz a bebês com baixo peso e prematuros. As doenças periodontais graves levam a um aumento na produção de prostaglandinas, que participam na contração uterina durante o trabalho de parto e podem induzir o parto prematuro ${ }^{(12)}$.

Durante a gestação as mulheres experimentam mudanças na sua cavidade bucal, sendo que as principais alterações são aquelas relacionadas com o aumento da vascularização da gengiva e a resposta exagerada dos tecidos moles do periodonto aos fatores locais. Ocorre aumento da mobilidade dentária, do fluido gengival e da profundidade da bolsa ${ }^{(21)}$. Para que se consiga restabelecer a saúde periodontal é necessário que se remova a placa bacteriana e o cálculo dental que a retém, e o melhor método para esse fim é a raspagem, alisamento e polimento dentário realizado pelo próprio paciente com o uso de escova e fio dental. A raspagem e higiene dentária associadas são importantes para promover a reinserção gengival, diminuindo a profundidade da bolsa ${ }^{(22)}$.

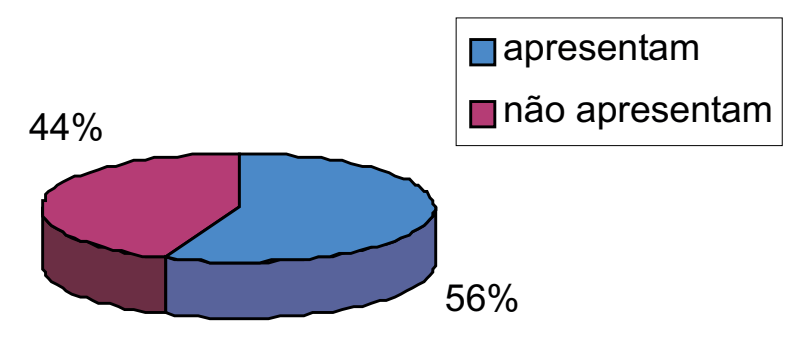

Figura 5 - Freqüência da presença de cálculo nas gestantes. Curitiba, 2003
A análise de dieta, no que se refere ao tipo de produto empregado para adoçar os alimentos, mostra que $100 \%$ das mulheres pesquisadas utilizavam açúcar na forma de adoçante, Figura 6 e 53\% delas possuíam uma freqüência diária alta de ingestão de açúcar sob outras formas de alimentos, Figura 7.

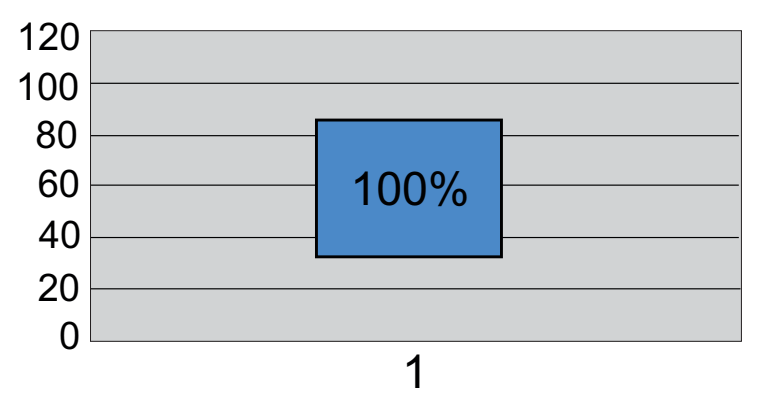

Figura 6 - Freqüência da utilização do açúcar para adoçar os alimentos. Curitiba, 2003

A paciente grávida apresenta um decréscimo da capacidade fisiológica do estômago durante o terceiro trimestre e pode ingerir menor quantidade de alimentos, porém com mais freqüencia. Suas refeições tornam-se hábitos constantes, à base de alimentos que podem ser altamente cariogênicos ${ }^{(21)}$. Estes dados são confirmados no presente estudo, em que todas as grávidas utilizavam o açúcar como adoçante e tinham uma alta freqüência de ingestão de açúcar na forma de alimentos ou para adoçar os alimentos.

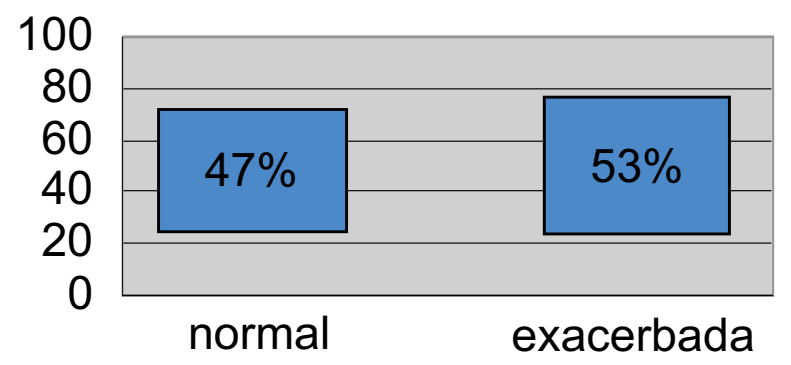

Figura 7 - Freqüência diária de ingestão de açúcar na forma de alimentos. Curitiba, 2003

Os dados relativos ao uso de açúcar justificam a preocupação com o papel da mulher como formadora de opinião, que tem grande influência sobre seu núcleo familiar, determinando muitos dos comportamentos que seus filhos terão. Os hábitos alimentares da gestante serão copiados por seus filhos, portanto uma gestante bem informada sobre a saúde e o impacto dos hábitos alimentares e de higiene sobre a saúde bucal é o primeiro passo para uma população livre de cárie ${ }^{(13)}$.

O exame bucal simplificado foi realizado em 
cada gestante e mostrou que $56 \%$ das grávidas apresentavam alto índice de cárie e, por conseqüência, alta atividade de cárie, Figura 8. Não houve relato de hábitos do uso cigarro, álcool, cafezinho, entre outros, entre as pacientes avaliadas.

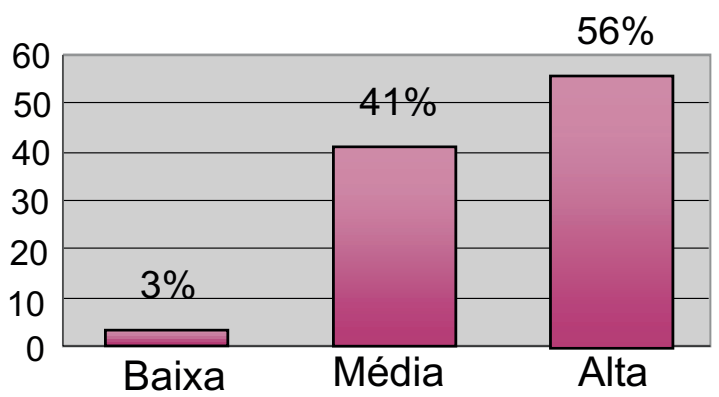

Figura 8 - Freqüência da atividade de cárie nas gestantes. Curitiba, 2003

\section{CONCLUSÃO}

Com base nos dados da pesquisa, chegamos às seguintes conclusões: a freqüência de escovação foi ruim em $50 \%$ das gestantes e $56 \%$ destas não utilizavam o fio dental durante a escovação. A alta atividade de cárie das gestantes pesquisadas pode ter como conseqüência a baixa freqüência de consulta ao dentista, de $77 \%$, e o hábito do uso de açúcar como adoçante e em ingestão diária na forma de alimentos, respectivamente $100 \% \mathrm{e}$ $53 \%$ de uso. A higiene bucal foi ruim ou regular em $70 \%$ das pacientes, demonstrando a necessidade do emprego de medidas de educação para saúde e promoção de saúde bucal neste grupo de gestantes, infocando a falta de higiene e dieta cariogência como fatores de risco às doenças bucais. Os programas de promoção da saúde e prevenção de doenças deverão considerar a mulher como uma formadora de opinião no núcleo familiar, e que seus conceitos em relação à saúde e doença serão adotados por seus filhos. A gestante com bons hábitos de higiene bucal os transmitirá para os filhos.

As alterações próprias da gestação expõem a mulher a um maior risco de doença bucal e somados a essas características relativas ao período gestacional, ainda temos dados que demonstram um déficit de cuidado com a higiene bucal e com os hábitos alimentares. Considerando, ainda, o papel da mulher na formação dos hábitos dos filhos, torna-se imprescindível o desenvolvimento de atividades de promoção da saúde bucal. O programa de Pré-Natal é um espaço privilegiado para trabalhar com as gestantes a importância da higiene e dos hábitos saudáveis, bem como a garantia de acesso à consulta odontológica para detecção precoce de patologias e respectivo tratamento.

\section{REFERÊNCIAS}

1. Ranali J, Andrade ED, Volpato MC. Pacientes gestantes - Profilaxia, tratamento e controle do paciente com doenças sistêmicas ou que requer cuidados especiais. In: Todescan FF, Bottino MA. Atualização na clínica odontológica - a prática da clínica geral. São Paulo: Artes Medicas; 1996. p.766.

2. Elias R. Odontologia de alto risco. Rio de Janeiro: Revinter; 1995.

3. Nascimento ZCP, Lopes WC. Gestante. Rev ROBRAC. 1996;20(6):27-33.

4. Fourniol Filho A. Pacientes especiais e a odontologia. São Paulo: Santos; 1998.

5. Pinto VG. Saúde bucal coletiva. $4^{\mathrm{a}}$ ed. São Paulo: Santos; 2000.

6. Argote LA, Valverde MM. La donación hace diferencia en el cuidado de padres y niños prematuros. Fam Saúde Desenv. 2002;4(1):7-15.

7. Wannmacher L, Ferreira MBC. Farmacologia clínica para dentistas. Rio de Janeiro: Guanabara Koogan; 1999.

8. Andrade ED. Terapêutica medicamentosa em odontologia. São Paulo: Artes Medicas; 1999.

9. Issler H, Leone, C, Marcondes E. Pediatria na atenção primária. São Paulo: Sarvier; 1999.

10. Buss PM. Uma introdução ao conceito de promoção da saúde. In: Czeresina D, Freitas CM, organizadores. Promoção da Saúde. Rio de Janeiro: Fiocruz; 2003.

11. Kramer PF, Feldens CA, Romano AR. Promoção de saúde bucal em odontopediatria: diagnóstico, prevenção e tratamento da cárie oclusal. São Paulo: Artes Médicas; 1997.

12. Martins VF. A importância da odontologia para as gestantes. Rev APCD. 2004, Set: 7-9.

13. Medeiros EB, Rodrigues MJ. Conhecimento das gestantes sobre a saúde bucal de seu bebê. Rev APCD. 2003;57(5):381-6.

14. Costa, ICC, Marcelino G, Berti GM, Saliba NA. Agestante 
como agente multiplicador de saúde. RPG Rev. 1998;5(2):87-92.

15. Rosell FL, Montandon-Pompeu AAB, Valsecki Jr A. Registro periodontal simplificado em gestantes. Rev Saúde Publ. 1999;33(2):157-62.

16. Peres SHCS, Cardoso MTV, Garcez RMVB, Peres AS, Bastos JRM. Tratamento alternativo de controle da cárie dentária no período materno-infantil. Rev Assoc Paul Cir Dent. 2001;55(5):346-50.

17. Fritscher AMG, Araújo DF, Figueiredo MC. Avaliação comparativa dos índices de cárie, placa visível e sangramento gengival de 50 pares mãe-filho. J Bras Odontopediat Odontol Bebe. 1998;1(4):34-42.

18. Triviños ANS. Introdução à pesquisa em ciências sociais: a pesquisa qualitativa em educação. São Paulo: Atlas; 1994

19. Ministério da saúde (BR). Conselho Nacional de Saúde. Diretrizes e normas regulamentadoras de pesquisa em seres humanos. Resolução n. 196, de 10 de outubro de 1996. Brasília, 1996.

20. Milanezi LA, Nagata MJH, Pescinini, LM, Lacerda Jr N. Uso dos agentes de limpeza dentária. Rev Gaúcha Odontol. 1994;42(2):101-4.

21. Oliveira MAM. Atendimento odontológico na gravidez. Santos: São Paulo; 1990.

22. Souza SMS, Duarte CA. Cálculo dentário-cáriedoença periodontal. Rev APCD 1990;44(5). 


\section{$\operatorname{Anexo} A$}

Instrumento de avaliação da qualidade da higiene bucal e dos hábitos alimentares em gestantes

1.Nome:

Idade:

Data de nascimento:

Exame realizado por: Data do exame:

2.Informações sobre dieta

Utiliza: ( ) Açúcar ( ) Adoçante ( ) Nenhum

Come doce? Sim ( ) Não ( ) Qual a freqüência da utilização destes alimentos por dia?

Durante a gravidez, houve modificação da dieta? Sim ( ) Não ( ).

Em caso afirmativo, para quais alimentos?

3.Informações sobre hábitos

Você tem algum hábito de uso dos abaixo relacionados?

( ) cigarro ( ) álcool ( ) chimarrão ( ) cafezinho ( ) outros

4.Informações sobre hábitos de higiene

\begin{tabular}{|l|l|l|l|}
\hline Hábito & Sim & Freqüência & Observações \\
\hline Escovação & & & \\
\hline Fio dental & & & \\
\hline
\end{tabular}

5.Exame periodontal
( ) Saudável ( ) Cálculo ( ) Sangramento Gengival ( ) GUNA ( ) Abscesso
( ) Gengivite ( ) Aumento de volume
( ) Presença de diastemas Quais dentes?
( ) Presença de apinhamento Quais dentes?

Risco à doença periodontal

( ) alto - tártaro e sangramento

( ) médio - inflamação/sangramento

( ) baixo - gengiva saudável

Exame da higiene oral

( ) Ruim - placa evidente/tártaro ( ) Regular-placa ( ) Boa

Atividade de cárie: ( ) mancha branca ( ) cárie aguda ( ) cárie crônica

Risco à cárie: ( ) alto ( ) médio $\quad$ ( ) baixo

Determinação de CPO-D e condições bucais 


\section{Anexo B}

\section{Odontograma}

\begin{tabular}{|l|l|}
\hline Restauração & Azul \\
\hline Cárie cavitada & Vermelho \\
\hline Mancha branca & Preto \\
\hline Restauração defeituosa & $\begin{array}{l}\text { Azul com círculo } \\
\text { vermelho }\end{array}$ \\
\hline Indicação exodôntica & X vermelho \\
\hline Extração & X preto \\
\hline Dente selado & Verde \\
\hline Selante defeituoso & $\begin{array}{l}\text { Verde com círculo } \\
\text { vermelho }\end{array}$ \\
\hline
\end{tabular}

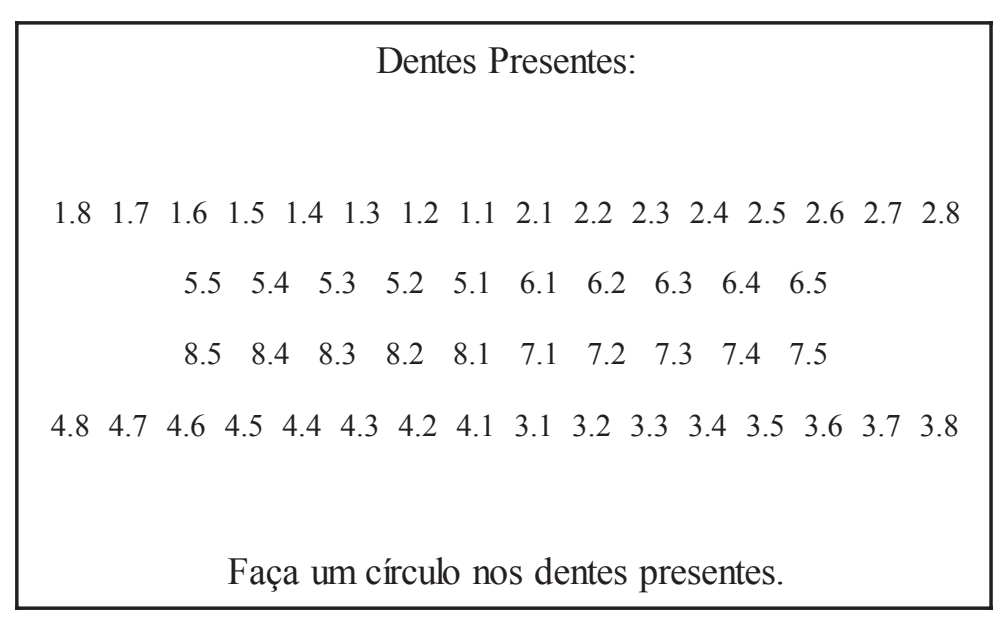

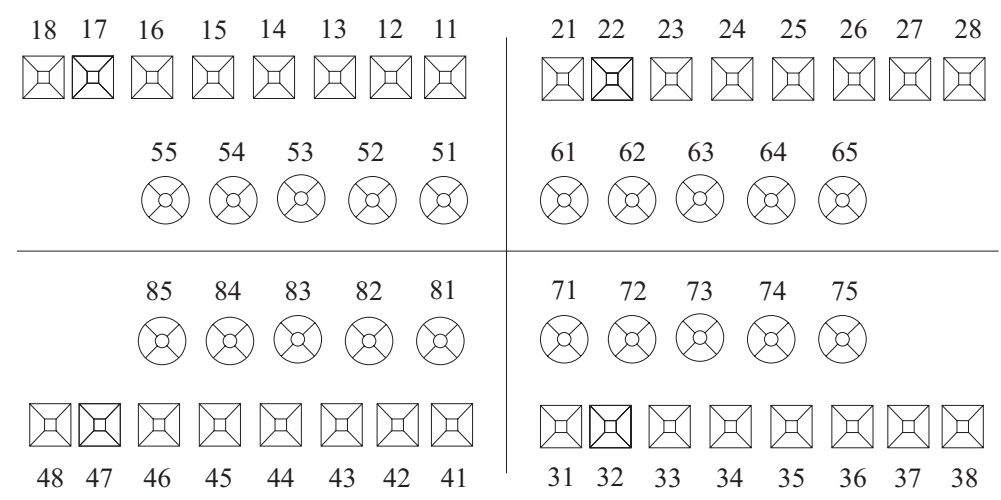

